\title{
Assessment of Nutritional Patterns of Pregnant Adolescents in Aswan City
}

\author{
Noha Anwar Mahmoud Ahmed, Nursing Teacher \\ Secondary Technical Nursing School, Aswan Governorate
}

Jilan Ali Ibrahim El Battawi, Assistant Professor

Obstetrics and Gynecologic Nursing, Faculty of Nursing, Alexandria University

\author{
Maha Mohamed El-Habashy, Assistant Professor \\ Obstetrics and Gynecologic Nursing, Faculty of Nursing, Alexandria University
}

\begin{abstract}
Adolescent pregnancy is a worldwide health problem. It has been considered as a major health problem to pregnant women and their newly born babies especially in developing countries to the extent that it received considerable attention. Objective: To assess nutritional patterns of pregnant adolescents in Aswan City. Settings: Ten Maternal and Child Health (M.C.H) centers in Aswan city were randomly chosen from the available 36 M.C.H centers, affiliated to the Ministry of Health. Subjects: A convenience sample of 300 pregnant adolescents aged 15-21 years was selected from the previous settings, (30 from each MCH center). Tool: Adolescent pregnant women nutritional patterns structured interview schedule was developed by the researcher. It entailed the following parts: Part one: Sociodemographic and reproductive history. Part two: Nutritional patterns structured interview schedule that comprised: $a$. Knowledge about nutrition and elements of balanced diet. $b$. Factors affecting study subject's choice of food. c. Knowledge about risks of malnutrition. $d$. Nutritional behaviors or habits of pregnant adolescents. Results: A poor total score regarding knowledge about nutrition and elements of balanced diet was obtained by $58.0 \%$ of the study subjects. Regarding factors that affect choice of food, nearly two thirds (63.3\%) of the study subjects' husbands were responsible for buying food. Choosing food was the responsibility of wives among $57.3 \%$ of the study subjects More than two-thirds of the study subjects always had fresh fruits, vegetables and dairy products at home both. Regarding knowledge about risks of malnutrition. Less than two-thirds (65.0\%) and slightly more than one third (34.0\%) of the study subjects gained poor and fair total score grade (respectively). On the other hand, the vast majority (94.3\%) of the study subjects gained good total score of nutritional habits. Conclusion: It was concluded that the majority of the study subjects gained good nutritional habits in spite of their poor knowledge. Many adolescents have poor diet quality and lack knowledge about the appropriate nutrition. As a result, engaging in unhealthy dietary practices. Recommendations: Improving the nutritional status of adolescent girls before and during pregnancy is recommended through providing necessary knowledge about the good eating habits and nutritional requirements. Enforce mass media should provide nutritional education programs to adolescents about importance of nutrition and risks of malnutrition especially for pregnant adolescents.
\end{abstract}

\section{Introduction}

WHO, defined pregnancy as a unique feminine experience and a critical period during women's life cycle. It is a normal process which results in a series of physiological and psychological changes to the expectant mother. Adolescent pregnancy is a global problem. The incidence of adolescent pregnancy and adolescent birth is widely divergent. In recent decades adolescent pregnancy has become an important health issue in a great number of 
countries. Worldwide, early childbearing is associated with higher risk of adverse reproductive outcomes among the youngest mothers and their newborns, as well as increased maternal and infant mortality ${ }^{(1-3)}$.

Maternal physiological changes during pregnancy or adaptations are involving all body' systems. Every change is aimed for the maintenance of the pregnancy, the development of the fetus, and preparation for labor and birth. The psychological changes occur not only as a result of the physiological alternations that occur but also due to the added responsibility associated with the new person coming to the family. Pregnancy provides the time for the woman to be prepared for labor and birth experience, complete the tasks of pregnancy, and accomplish the role of mother. Motherhood is an irrevocable change in women's life, progressively becoming part of a woman's total identity. These psychological adaptations and development of the woman identity as a mother are crucial aspects of the childbearing cycle ${ }^{(4-6)}$.

The total fertility rate in 2011 in some countries worldwide per 1000 women was as follows: the United States 1.9 women, the United Kingdom 2.0 women, South Africa 2.4 women, Tanzania 5.4 women, Jordan 3.4 women, Kuwait 2.7 women, and Iraq 4.1 women. In Egypt the total fertility rate of Egyptian women ranged from 2.852.9 children born/ 1000 woman between the year of $2011-2013^{(7,8)}$. About 16 million girls aged 15-19 years old worldwide give birth each year. $95 \%$ of these births occur in the developing countries. The proportion of births that take place during adolescence in 2011/1000 girls is about 9 girls/1000 girls in china and 53 girls/1000 girls in South Africa. The UK has the highest teenage pregnancy rate in Western Europe that is as 26 girls/1000. In the United States of America, about 1 million teenagers or $5-8 \%$ of the teenage population become pregnant each year ${ }^{(9-11)}$. In the Arab region, one in seven girls marries before her being 18 years old age. The Analysis of Demographic and Health Surveys in Egypt 2008 indicated that the teenage pregnancy rate varied from $1 \%$ in urban areas of Lower Egypt to $6 \%$ in rural areas of Upper Egypt. The rate of adolescent pregnancy in Egypt in 2011 was $44 / 1000$ girls aged $15-19$ years ${ }^{(12-15)}$.

WHO defined adolescence as a time of age between 11 to 21 years old, when the lifestyle patterns of behavior are being formed. It is divided into three stages: Early Adolescence (ages 11-14 years) which is called puberty period, Middle adolescence (ages 15-17) years and late adolescence (ages 18-21) years. The adolescence period, is characterized by rapid physiological, psychological and social changes ${ }^{(16,17)}$. On the other hand, every adolescent has certain needs as, nutrition, sleep, rest, love, security, approval, independence, and selfexpression. There is no doubt that nutrition is a basic human need and a cornerstone of good health and wellbeing across the entire life $^{(18,19)}$

Adolescence is potentially a critical window for establishing healthy lifestyle choices and development of dietary behaviors that continue into adulthood and may decrease the risk of chronic diseases later in life ${ }^{(20,21)}$. Adolescence is a time of growth and development, with totally high nutrient needs. Dietary inadequacy is more common among adolescent especially for $\operatorname{girls}^{(22,23)}$. Moreover, adolescents are vulnerable to malnutrition because they are growing faster than any time after their first year of life. Many adolescents have poor diet quality and lack knowledge about the appropriate nutrition. As a result, engaging in unhealthy dietary practices and having erratic eating patterns that include high intakes of fast foods and foods high in fat, sugar, inadequate intake of calcium, and low intakes of fruits and vegetables ${ }^{(24,25)}$. These habits are risky especially for girls who may marry and become pregnant. These habits may not change during pregnancy, so they are likely to exhibit food preferences, eating behavior, and lifestyle 
habits that are similar to their non-pregnant peers. So, special care should be given to nutritional inadequacy in pregnant female adolescents, to cope with the additional nutritional demands of pregnancy, childbirth and lactation as well as to their needs of nutrition to their growth and development as adolescents ${ }^{(26,27)}$.

Pregnant adolescents face many complications such as: increased risk of preterm labor, intrauterine growth retardation, cesarean delivery, low birth weight, and increase maternal morbidity and mortality $^{(28,29)}$. Multiple factors may influence an adolescent's susceptibility to eating and thus act as barriers to healthy eating. These factors are represented in two dimensions: the first one is the social factor, while the second dimension is represented in the economic factor. Social factors such as family, peer, and media are considered a powerful influence on food choice and nutrition-related behaviors for adolescents $^{(30-32)}$. Parents are the primary source of nutritional information that has a strong influence on nutritional choices. The economic factors would have the greatest influence on the food choice of low-income adolescents. The low-income groups have a greater tendency to consume unbalanced $\operatorname{diets}^{(33,34)}$

Health professionals recognize that attention should be paid to monitor the nutritional status of vulnerable groups' especially pregnant female adolescents. Moreover, good nutrition is essential to help support a successful pregnancy and breastfeeding ${ }^{(35)}$.

\section{Aim of the Study}

Assess nutritional patterns of pregnant adolescents in Aswan City.

\section{Research Question:}

What are the nutritional patterns of pregnant adolescents in Aswan City?

\section{Operational Definition:}

Nutritional pattern in this context means: a .Knowledge about nutrition and elements of balanced diet. b. Factors affecting their choice of food. c. Knowledge about risks of malnutrition. d. Behaviors or patterns of pregnant adolescents.

\section{Materials and Method}

\section{Materials}

Design: An exploratory descriptive design was used.

Settings: Data was collected from (ten) Maternal and Child Health (M.C.H) centers in Aswan city chosen randomly from the available 36 M.C.H centers, which are affiliated to the Ministry of Health.

Subjects: A convenient sample of 300 pregnant adolescents were conveniently selected from the previously mentioned settings, 30 from each $\mathrm{MCH}$ center and fulfilling the following criteria: Age ranged between: 15 to 21 a years old (middle \&late adolescents). Normal pregnancy without ; previous or associated health problems.

\section{Tool:}

Tool I: Adolescents pregnant women nutritional patterns structured interview schedule

It was developed by the researchers after reviewing the related literature to collect the necessary data. It entailed the following parts:

Part One: Socio- demographic and reproductive history data: Sociodemographic data such as: age, level of education, occupation, age of marriage, marital status, , residence, type of family, number of family member, number of rooms, crowding index and income as well as parents' education. Reproductive health data such as: number of gravidity, number of parity, number of abortions, duration of present pregnancy, number of living 
children, number of dead children, and type of last delivery.

$\begin{array}{lll}\text { Part Two: } & \begin{array}{c}\text { Nutritional patterns } \\ \text { interview }\end{array} \\ \text { structured } & \text { schedule: }\end{array}$

A- Knowledge about nutrition and elements of balanced diet. It consists of 16 questions. Subject response for each question: if correct and complete answer "2", correct and incomplete "1" and wrong and/or don't know answer " 0 ". The total score ranges from 0 to 32 as follows: Poor knowledge $(0<11)$; Fair knowledge $(11-<22)$ Good knowledge (22-32). B- Factors affecting their choice of food. C- Knowledge about risks of malnutrition. It consists of 11 questions. Subject response for each question: correct and complete answer "2", correct and incomplete answer " $1 "$ and wrong and /or don't know answer "0". The total score ranges from 0 to 22 as follows: Poor knowledge (0-<7); Fair knowledge (7$<14)$; Good knowledge (14-22). DBehaviors or patterns of pregnant adolescents which contain 24 items to assess their nutritional habits during pregnancy. Each item is rated on a 3 -point Likert scale ranging from 1 to 3 ; never= (1); sometimes $=(2)$; always $=(3)$ : for positive items while negative were reversed as, never $=(3)$, sometimes $=(2)$ : always $=(1)$. The total score ranged from $24-72$ as follows: Bad habits $(24<40)$, Fair habits $(40-<56)$; Good habits (56- 72).

\section{Method}

- Approval was obtained from the ethical committee of the faculty of nursing- Alexandria University and the responsible authorities of the study settings.

- Development of the tool: Structured interview schedule was developed by the researcher after extensive review of recent literature. Then it was tested for content validity by five experts in the field of obstetric nursing in nursing faculty of Alexandria. The recommended modifications were done and the final interview schedule was finalized. The tool was also tested for reliability by using "ALPHA CRONBECH" test. The result was .895 for nutritional knowledge and elements of balanced diet, 0.872 for knowledge of about risks of malnutrition, 0.805 for food available at home and 0.772 for nutritional habits which indicated an acceptable reliability for the tool.

- Pilot study: After the development of the interview schedule, a Pilot study was carried out on 30 pregnant adolescents $(10 \%)$ of the study sample (these were excluded from the study sampel). The purpose of the pilot study was to: Ascertain relevance and content validity of interview schedule. Detect any problem peculiar to the statements as sequence and clarity that might interfere with the process of data collection. Estimate the time needed to complete the interview schedule. Results of the pilot study: After conducting the pilot study, it was found that the sentences of the interview schedule were clear and relevant; however, few words were modified. Following this pilot study the interview schedule was reconstructed and made ready for use.

- Collection of data: Each subject was individually interviewed before or after antenatal medical checkup. The researcher explained the purpose of the study to each pregnant adolescent.

\section{Ethical considerations:}

The nature and purpose of the study were explained to the subjects participating in the study. All information obtained from the participants was treated with the utmost confidentiality. Clarification of any point in the study was provided to the study subjects 
if needed. Participants were also informed about their right to withdraw from the study at anytime without giving a reason. An oral consent to participate in the study was obtained.

\section{Statistical Analysis}

Statistical analysis was done by the researcher. After data were collected it was revised, coded and fed to statistical software IBM SPSS version 20. The given graphs were constructed using Microsoft excel software. All statistical analysis was done using two tailed tests and alpha error of 0.05 . $\mathrm{P}$ value less than or equal to 0.05 was considered to be statistically significant. A descriptive and analytical statistics were used such as percentages. Pearson's chi square test to test the relationship between variables, Mont Carlo exact test and Fishers exact test were also used to alternatives for the Pearson's chi square test if there were many small expected values.

\section{Results}

Figure (1) demonstrates the percentage distribution of the pregnant adolescents according to their total scores of nutritional knowledge and elements of balanced diet. It was noticed that near three fifths $(58.0 \%)$ of the study subjects gained poor total score. While only $1.0 \%$ of them gained good total score.

Table (1) clarifies the number and percentage distribution of the pregnant adolescents according to their nutritional knowledge and elements of balanced diet. It was obvious that $91.3 \%, 70.3 \%, 70.3 \%$, $67.3 \%, 66.0 \%$ and $65.6 \%$ of the study subject answered wrong and/or don't know about the importance of fat, carbohydrates, iron, calcium, protein, and vitamins respectively. In addition, $88.7 \%$ and $70.3 \%$ of the study subjects answered correct and incomplete related to foods to be decreased or to be increased during pregnancy respectively. Moreover $73.3 \%, 66.3 \%$ and $66.0 \%$ of them answered correct and incomplete about the most importance food rich in vitamins, iron and carbohydrates respectively. Finally, none of the subjects gave correct and complete answered related to all items of nutritional knowledge except $(15.0 \%, 6.3 \%, 4.7 \%, 3.3 \%, 1.0 \%$ and $0.7 \%)$ answered correct and complete related to food to be increased during pregnancy, food rich in protein, food rich in calcium, food rich in fat, elements of healthy food, food that should be decrease during pregnancy and food rich in vitamins respectively.

Table (2) shows the number and percentage distribution of the pregnant adolescents according to factors that affect choice of food. Regarding family income, the table shows that more than one-half $(52.6 \%)$ of the study subjects found it is not enough to satisfy their food needs. The table also shows that near two thirds $(63.3 \%)$ of the husbands' of the study subjects are responsible for buying food, followed by wife and mother in low which constitute $16.7 \%$ for both. In addition, regarding choosing and preparing food, it was noticed that more than one half $(57.3 \%)$ and the majority $(92.0 \%)$ of the study subjects, the wife is the responsible person for choosing and preparing food.

Figure (2) displays the percentage distribution of the pregnant adolescents according to their total score of knowledge about risks of malnutrition. It was found that less than two thirds $(65.0 \%)$ and slightly more than one third $(34.0 \%)$ of the study subjects gained poor and fair total score respectively. While only $(1.0 \%)$ of the study subjects gained good total score.

Table (3) illustrates the number and percentage distribution of the pregnant adolescents according to their knowledge about risks of malnutrition. It was found that the majority $(91.3 \%)$ of the study subjects answered wrong and don't know about risks of vitamins deficiency in eating for mother during pregnancy, while $77.7 \%$, $66.0 \%, 55.0 \%$ and $49.0 \%$ of the study subjects answered correct and incomplete about risks of lack of eating for mother 
during pregnancy, risks of inadequate eating for fetus during pregnancy, risks of iron deficiency in eating for mother during pregnancy and risks of calcium deficiency in eating for mother during pregnancy respectively. In addition, only $36.7 \%$ and $17.0 \%$ give correct and compete answer about risks of calcium deficiency in eating for fetus during pregnancy and risks of increased food intake for fetus during pregnancy respectively.

Figure (3) illustrates the percentage distribution of the pregnant adolescents according to their total score of nutritional habits. It was found that the vast majority $(94.3 \%)$ of the study subjects gained good total score and $5.7 \%$ of study subjects gained fair total score of their nutritional habits.

Table (4) illustrates the relationship between the nutritional knowledge and elements of balanced diet of the pregnant adolescents and their socio-demographic data. Regarding the age, it was noticed that $84.2 \%, 52.8,55.1$ of the study subjects who were in the age between $15-<17,17-<19$, 19-21 years had poor total score of nutritional knowledge respectively while only $(1.9 \%)$ of the study subjects, who were in the age between 19-21 years gained good total score. Adolescent age found to be associated with poor knowledge about nutritional knowledge and elements of balanced diet. There was a statistically significant correlation found between the nutritional knowledge of the study subjects and their age $(\mathrm{P}=0.005)$.

In relation to the educational level, $(81.0 \%)$ of the study subjects who got university education gained fair total score. On the contrary, only $(1.8 \%)$ of the study subjects who got secondary education gained good total score. There was a statistically significant correlation between the nutritional knowledge of the study subjects and their educational level $(\mathrm{P}=0.000)$.
Considering the occupation, it was obvious that less than two thirds $(62.4 \%)$ and more than one third $(37.6 \%)$ of the study subjects who were housewives gained poor and fair total score respectively regarding the nutritional knowledge. On the other hand only $(8.8 \%)$ of the study subjects who were working gained good total score. There was a statistically significant correlation between the nutritional knowledge of the study subjects and occupation $(\mathrm{P}=0.000)$.

Concerning the age of marriage, it was found that less than two thirds $(62.5 \%)$ of study subjects who married at the age 17 to -<19 years obtained poor total score, while only $(5.2 \%)$ of study subjects who married at the age 19-21 years gained good total score. There was a statistically significant correlation between the nutritional knowledge of the study subjects and their age of marriage $(\mathrm{P}=0.007)$.

As regards the father's education, it was found that one half $(50.0 \%)$ of the study subjects whose fathers got university education gained poor and fair total score respectively. Only (3.5\%) of the study subjects whose fathers were illiterate gained good total score. There was a statistically significant correlation between the nutritional knowledge of the study subjects and their father's education $(\mathrm{P}=0.019)$.

As regards the mother's education, it was found that slightly less than three quarters $(73.3 \%)$ of the study subjects whose mothers got university education, gained fair total score. Only (2.4\%) of the study subjects whose mothers were illiterate gained good total score. There was a statistically significant correlation between the nutritional knowledge of the study subjects and their mother's education $(\mathrm{P}=0.009)$.

In relation to the type of the family, more than one half $(58.8 \%)$ of study subjects who lived in a nuclear family gained poor total score regarding the nutritional knowledge. On the other hand 
only $(5.3 \%)$ of the study subjects whose crowding index $<1$ gained good total score There was a statistically significant correlation between the nutritional knowledge of the study subjects and their crowding index $(\mathrm{P}=0.007)$.

Moreover, one half $(50.0 \%)$ of study subjects who had more than enough income, gained poor and fair total score respectively. However, there is no statistically significant correlation between the nutritional knowledge of the study subjects and their type of family as well as their income.

Table (5) illustrates the relationship between knowledge about risks of malnutrition of the pregnant adolescents and their socio-demographic data. Regarding the age, it was noticed that as much as $(84.2 \%)$ of the study subjects, who were in the age between $15-<17$ years gained poor total score regarding knowledge about risks of malnutrition. However, only $(1.9 \%)$ of the study subjects, who were in the age between 19-21 years gained good total score. There was a statistically significant correlation between knowledge about risks of malnutrition of the study subjects and their age $(\mathrm{P}=0.019)$.

In relation to the educational level slightly more than one half $(52.4 \%)$ of the study subjects who got university education, gained poor total score. On the other hand, only $(3.6 \%)$ of the study subjects who got preparatory education, gained good total score. There was a statistically significant correlation between knowledge about risks of malnutrition of the study subjects and their educational level $(\mathrm{P}=0.004)$.

Considering the occupation, it was obvious that slightly more than two thirds $(66.9 \%)$ of the study subjects who were housewives gained poor total score. On the other hand only $(8.8 \%)$ of the study subjects who were working gained good total score. There was a statistically significant correlation between knowledge about risks of malnutrition of the study subjects and their job $(\mathrm{P}=0.000)$.
Concerning the age of marriage it was found that slightly less than two thirds $(64.7 \%)$ of the study subjects who married at the age $17-<19$ years obtained poor total score regarding knowledge about risks of malnutrition, while $2.8 \%$ of the study subjects who married at the age $15-<17$ years gained good total score.

Regarding the father's education it was found that one half $(50.0 \%)$ of the study subjects whose fathers got university education, gained poor and fair total score both respectively. Only (6.1\%) of the study subjects whose fathers were just read and write gained good total score. There was a statistically significant correlation between knowledge about risks of malnutrition of the study subjects and their father's education $(\mathrm{P}=0.001)$.

As regards mother's education, it was found that slightly less than three quarters $(73.3 \%)$ of the study subjects whose mothers got secondary education, gained poor total score. Only $(6.4 \%)$ of the study subjects whose mothers were just read and write gained good total score. There was a statistically significant correlation between knowledge about risks of malnutrition of the study subjects and their mother's education $(\mathrm{P}=0.009)$.

In relation to the type of the family, slightly less than two thirds $(65.3 \%)$ of the study subjects who live in a nuclear family gained poor total score, while only $1.4 \%$ of them got good total score .

On the other hand, only $(1.3 \%)$ of the study subjects whose crowding index 1-2, gained good total score. However, more than one half $(55.9 \%)$ of the study subjects who had more than enough income, gained poor total score. There was a statistically significant correlation between the knowledge about risks of malnutrition of the study subjects and their income $(\mathrm{P}=0.010)$. However, there is no statistically significant correlation between the knowledge about risks of malnutrition of the study subjects 
and their age of marriage and their type of family as well as their crowding index.

Table (6) illustrates the relationship between the nutritional habits of the pregnant adolescents and their sociodemographic data. Regarding the age, it was noticed that the vast majority $(98.1 \%)$ of the study subjects who were in the age between 19-21 years gained good total score regarding the nutritional habits, while $(10.4 \%)$ of the study subjects who were in the age between $17-<19$ years gained fair total score. There was a statistically significant correlation between the nutritional habits of the study subjects and their age $(\mathrm{P}=0.012)$.

In relation to the educational level all $(100.0 \%)$ of the study subjects who were illiterate and who got university education gained good total score regarding nutritional habits both respectively. On the other hand $(13.0 \%)$ of the study subjects who read and write gained fair total score regarding nutritional habits.

Considering occupation, it was obvious that the majority (94.7\%) and (91.2\%) of the study subjects who were housewives and working gained good total score regarding the nutritional habits respectively.

Concerning the age of marriage, it was found that $100 \%, 96.3 \%, 88.7 \%$ of the study subjects who married at the age 19 $21,17-<19$ and $15-<17$ years obtained good total score respectively. There was a statistically significant correlation between the nutritional habits of the study subjects and their age of marriage $(\mathrm{P}=0.004)$.

Regarding the father's education, it was found that all $(100 \%)$ of the study subjects whose fathers got preparatory and university education gained good total score both respectively. As regards the mother's education, it was found that all $(100.0 \%)$ of the study subjects whose mothers got preparatory and university education gained good total score both respectively.

In relation to the type of the family, the vast majority $(94.9 \%)$ of the study subjects who lived in a nuclear family gained good total score of nutritional habits followed by $92.9 \%$ of the study subjects who lived in extended family. On the other hand, $100 \%$, $93.9 \%$, and $75.0 \%$ of the study subjects whose crowding index $<1,1-2,3+$ gained good total score of nutritional habits. There was a statistically significant correlation between the nutritional habits of the study subjects and their crowding index $(\mathrm{P}=0.003)$,

All the study subjects (100.0\%) who had more than enough income gained good total score of nutritional habits. There was a statistically significant correlation between the nutritional habits of the study subjects and their income $(\mathrm{p}=0.000)$.

However, there is no statistically significant correlation between the nutritional habits of the study subjects and their education, their occupation, their father's education as well as their mother's education.

\section{Discussion}

Adolescence is a period of preparation for adulthood. During this time several keys of developmental tasks are undertaken. These include physical and sexual maturation, movement toward social and economic independence, as well as the development of identity ${ }^{(36)}$. Every adolescent has certain needs as, nutrition, sleep, rest, love, security, approval, independence, and self-expression ${ }^{(37)}$. Adolescent pregnancy introduces a multitude of concerns for both the mother and the fetus; one of these concerns is nutrition. Good nutrition is essential to help support a successful pregnancy and breastfeeding, and it is also vital for the mother and fetus. Women planning a pregnancy should follow a balanced nutrient-rich diet ${ }^{(26)}$. It affects the growing baby indirectly via maternal-fetal transfer, and directly during postpartum, via lactation. Pregnancy represents an ideal time for health promotion activities. Many women, including adolescents, are interested and 
willing to change health behaviors hoping that they will deliver a healthy infant ${ }^{(38)}$.

The present study revealed lack of nutritional knowledge and elements of balanced diet among the pregnant adolescents. Near to three fifths of the pregnant adolescent gained poor total score of nutritional knowledge (figure 1). This result is consistent with the findings of two other studies. Firstly, Yassin $\mathrm{S}$ et al. $(2004)^{(39)}$ they conducted study "Factors affecting dietary practices among adolescent pregnant women in Alexandria" indicated their $61.7 \%$ of the study subjects had poor knowledge about nutrition during pregnancy $^{(39)}$. Secondly Shaaban S et al.'s (2009) ${ }^{(26)}$ study titled "Nutritional Knowledge and Attitude of Adolescent School Girls Living in Cairo" who studied "Nutritional Knowledge and Attitude of Adolescent School Girls Living in Cairo" They reported that $<50 \%$ of their study subjects had poor knowledge regarding nutrition. The similarity between the results of these studies may be related to the educational level of shaaban's subjects, as half of them were in private secondary schools. He justified that there is a difference between the graduates from governmental school and the graduates from private schools, as private school graduates seem to be more knowledgeable in general $^{(26)}$.

On the contrary, the findings of Özünlü \& Cetinkaya $(2013)^{(40)}$ who had studied "The relation between pregnant adolescents' attitudes toward nutrition and weight gain during pregnancy and hemoglobin level" had reported that $(61.2 \%)$ of their study subjects had a good knowledge. Although the age of the study subjects in Özünlü \& Cetinkaya is similar to the age of present study subjects ${ }^{(40)}$. Moreover, the finding of the current study revealed that around two thirds of the current study subjects answered correctly but incomplete about the source of food elements as carbohydrate, vitamins, iron and calcium as well as, more than one half of them don't know the healthy food groups (table 1). This finding is similar with the study of Daba G et al. (2013) ${ }^{(41)}$ who studied "The assessment of knowledge of pregnant mothers on maternal nutrition and associated factors in Guto Gida Woreda, east Wollega zone, Ethiopia". His study revealed that less than two thirds $(64.4 \%)$ of his study subjects were found to be knowledgeable about nutrition during pregnancy $^{(41)}$. In contrast, Alam $\mathrm{N}$ et al. (2010) who studied "Nutritional status, dietary intake, and relevant knowledge of adolescent girls in rural Bangladesh" indicated that more than one-half of his study subjects could not name the main food sources of energy and sources of $\operatorname{protein}^{(42)}$.

The current study revealed lack of knowledge about risks of malnutrition among all the pregnant adolescents. Less than two thirds of the pregnant adolescents gained poor total score of knowledge about risks of malnutrition as they couldn't answer the risks of inadequate nutrition during pregnancy (figure $\mathbf{2} \&$ table 3 ). This finding is in harmony with the study of Daba $G$ et al. (2013) who revealed that $65.2 \%$ of his study subjects didn't answer the question of inadequate nutrition can cause miscarriage and/or preterm birth ${ }^{(41)}$.

The similarity between the present study and Daba may be attributed to that the two studies were done in the same economic status as more than three quarters of Daba's and the present study subjects had low income which prevented them to access knowledge. In addition, slightly less than two thirds of Daba's subjects were illiterate and therefore, they lacked the awareness about malnutrition and its risks during pregnancy $^{(41)}$.

Adolescence is an important time for establishing healthy dietary habits and enhancing nutritional habits during pregnancy which may improve birth outcomes ${ }^{(16)}$. The total score of nutritional habits was good by the majority of the current study subjects (figure 3). This finding is in accordance with, Wise et al. 
$(2011)^{(43)}$ who studied "adolescent views of healthy eating during pregnancy". They reported that the pregnant adolescents ate three or more meals a day. The equivalence of good nutritional habits between the current study and Wise may be attributed to that pregnancy motivates pregnant adolescents to have good pregnancy outcomes and healthy children even though they are adolescents characterized by bad nutritional behaviors as well as low socioeconomic status $^{(43)}$.

On the contrary, the current finding is not in line with the study of Özünlü\& Cetinkaya $(2013)^{(40)}$ who indicated that more than one half $(57.1 \%)$ of their study subjects had fine total score of nutritional habits. This resulted from eating food that contained high fat, sugar and consume tea or coffee which led to unhealthy eating practices. The discrepancy between the present study and Özünlü\& Cetinkaya may be attributed to that the study subjects choice of food was influenced by taste, convenience and $\operatorname{cost}^{(39)}$. The current study revealed that the total score of nutritional habits was good by the majority of the study subjects, but near to three fifths of them gained poor total score of nutritional knowledge (figure 1 \& 3). It is known that pregnancy can enhance the woman`s dietary practice. It is also known that nutritional knowledge by itself may not be enough to encourage healthy dietary behaviors to reach good pregnancy outcomes.

In the current study revealed a relationship between the nutritional knowledge and socio demographic status of the study subjects. There was a statistically significant correlation between nutritional knowledge and elements of balanced diet of the study subjects and their age, educational level, occupation, age of marriage, crowding index, fathers and mothers education. On the other hand, there was no statistically significant correlation between the nutritional knowledge of the study subjects and their type of family as well as their income (table 4). This finding is in line with three studies. The first one is the study of Hassan M (2012) ${ }^{(44)}$ who studied "Relationship between socio-economic characteristics, health status and nutritional awareness of pregnant women". It is worth mentioning that positive statistically significant correlation was found between the nutritional knowledge of her study subjects and the mother's education $(\mathrm{P}<0.01)$ as well as the father's education $(\mathrm{P}<0.05)^{(44)}$. The second one is the study of Daba G et al. (2013) $)^{(40)}$ who indicated that there was a positive statistically significant correlation between nutritional knowledge of their study subjects and the educational status as well as their family income ( $P$ $<0.001)$. This is may be attributed to the fact that near two thirds of their study subjects were illiterate and more than three quarters have low family income. The third one is of Mirsanjari M et al. (2012) ${ }^{(45)}$ who studied "Relationship between nutritional knowledge and healthy attitude and practice during pregnancy". It showed that there was a statistically significant correlation between nutritional knowledge of the study subjects and their household size, occupation, educational level and monthly income $^{(45)}$.

The current study revealed a relationship between the knowledge about risks of malnutrition and socio demographic status of the study subjects. There was a statistically significant correlation between the knowledge about risks of malnutrition of the study subjects and their age, education, occupation, father education, mother education and income. On the other hand, there was no statistically significant correlation between the knowledge about risks of malnutrition of the study subjects and their age of marriage, type of family and crowding index (table 5). This may be attributed to the fact that more than one third of the current study subjects gained no or low educational level which may be a problem to access knowledge about pregnancy and nutrition. In the current study there was a relationship between the nutritional habits and socio demographic 
status of the study subjects. There was a statistically significant correlation between nutritional habits of the study subjects and their age, age of marriage, crowding index and income. On the other hand, there was no statistically significant correlation between nutritional habits of the study subjects and their education, job, father education, mother education and type of family (table 6). Finally, pregnancy represents an ideal time for health promotion activities as well as improves nutritional behaviors. Adequate nutritional intake is important especially during pregnancy as well as for adolescent girls to have healthy pregnancy and desired birth outcomes. Therefore, attention should be taken to monitor the nutritional status of vulnerable groups' especially female adolescents. In addition, should be increased the nutritional knowledge of pregnant adolescents to be able practices their nutritional habits properly.

\section{Conclusion}

Based on the current study results, it can be concluded that the majority of the study subjects had poor knowledge regarding nutritional knowledge and elements of balanced diet; as well as knowledge about risks of malnutrition. The adolescent pregnant instead of their poor knowledge, the study revealed that the majority of them gained good nutritional habit.

\section{Recommendations}

1- Every chance should be used to educate adolescents about healthy food during antenatal follow up.

2- Mass media should provide nutritional education programs to counsel adolescents about importance of nutrition and risks of malnutrition.
3- Upgrading the nutritional information in primary and secondary school curriculum to include the needed information and guidelines for healthy food, elements of nutrition, and its importance for the mother and fetus.

4- Enforce training programs to be carried out for nurses working in antenatal units to enrich their knowledge regarding the importance of maternal nutrition during pregnancy and risks of malnutrition. 


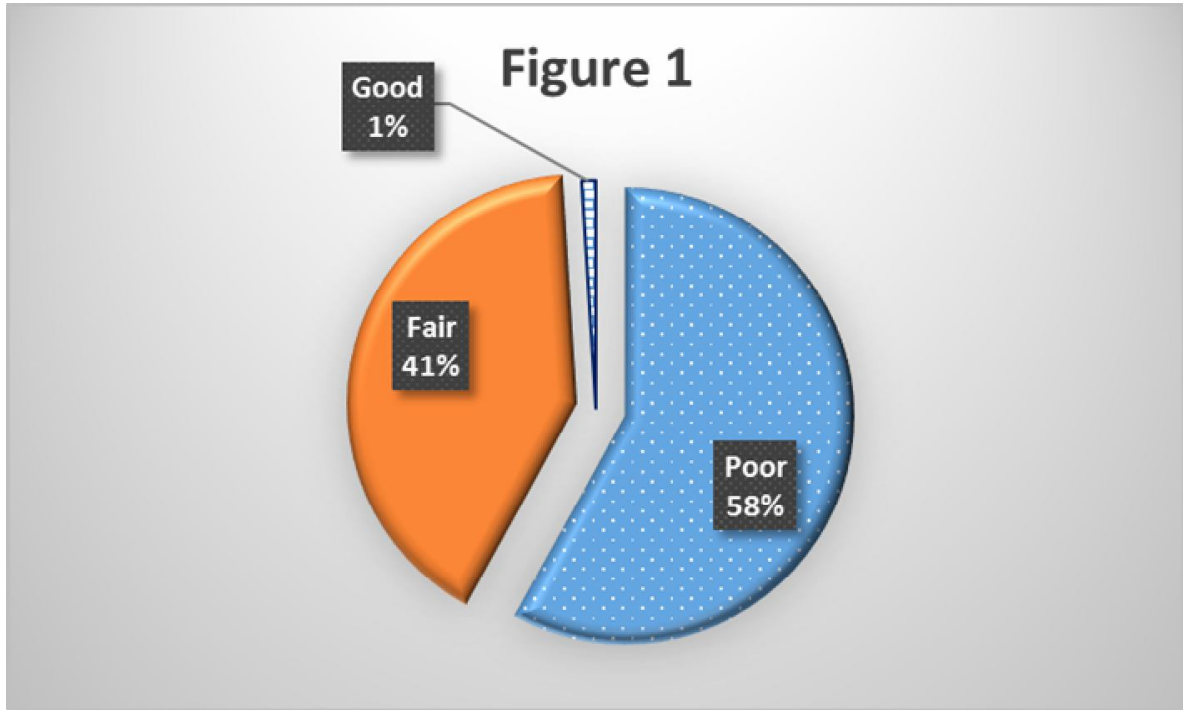

Figure (1): Percent distribution of the study subjects according to their total scores regarding nutrition knowledge and elements of balanced diet 
Nutritional Patterns of Pregnant Adolescents

Table (1): Number and percent distribution of the pregnant adolescents according to their nutritional knowledge and elements of balanced diet

\begin{tabular}{|c|c|c|c|c|c|c|}
\hline \multirow{3}{*}{ Nutritional knowledge and element of balanced diet } & \multicolumn{6}{|c|}{$\begin{array}{l}\text { Pregnant adolescents } \\
\qquad(\mathrm{n}=300)\end{array}$} \\
\hline & \multicolumn{2}{|c|}{$\begin{array}{c}\text { Wrong \&/or don't } \\
\text { know }\end{array}$} & \multicolumn{2}{|c|}{ Correct \& Incomplete } & \multicolumn{2}{|c|}{ Correct \& complet } \\
\hline & & $\%$ & No. & $\%$ & No. & $\%$ \\
\hline What are the healthy food groups? & 173 & 57.7 & 127 & 42.3 & 0 & 0.0 \\
\hline What are elements of the healthy food? & 151 & 50.3 & 146 & 48.7 & 3 & 1.0 \\
\hline What are the foods you should increase during pregnancy? & 44 & 14.7 & 211 & 70.3 & 45 & 15.0 \\
\hline What are foods you should decrease during pregnancy? & 31 & 10.3 & 266 & 88.7 & 3 & 1.0 \\
\hline What is the importance of protein? & 198 & 66.0 & 102 & 34.0 & 0 & 0.0 \\
\hline Which food is rich in protein? & 109 & 36.3 & 172 & 57.3 & 19 & 6.3 \\
\hline What is the importance of carbohydrates? & 211 & 70.3 & 89 & 29.7 & 0 & 0.0 \\
\hline Which food is rich in carbohydrates? & 102 & 34.0 & 198 & 66.0 & 0 & 0.0 \\
\hline What is the importance of fat? & 274 & 91.3 & 26 & 8.7 & 0 & 0.0 \\
\hline Which food is rich in fat? & 150 & 50.0 & 140 & 46.7 & 10 & 3.3 \\
\hline What is the importance of Vitamins? & 197 & 65.6 & 101 & 33.7 & 2 & 0.7 \\
\hline Which food is rich in Vitamins? & 77 & 25.7 & 220 & 73,3 & 3 & 1.0 \\
\hline What is the importance of Iron? & 211 & 70.3 & 89 & 29.7 & 0 & 0.0 \\
\hline Which food is rich in Iron? & 101 & 33.7 & 199 & 66.3 & 0 & 0.0 \\
\hline What is the importance of Calcium? & 202 & 67.3 & 98 & 32.7 & 0 & 0.0 \\
\hline Which food is rich in Calcium? & 95 & 31.6 & 191 & 63.7 & 14 & 4.7 \\
\hline
\end{tabular}

MeantSD: $26.8 \pm 14.7$ 
Table (2): Number and percent distribution of the study subjects according to factors that affecting choice of food

\begin{tabular}{||l|c|c||}
\hline \multirow{2}{*}{ Factors that affect choice of food } & \multicolumn{2}{|c|}{ (n=300) } \\
\cline { 2 - 3 } Family income & No. & \% \\
More than enough & 53 & 17.7 \\
Just enough & 89 & 29.7 \\
Not enough & 158 & $\mathbf{5 2 . 6}$ \\
\hline \# Person who buys food & & \\
Wife & 50 & 16.7 \\
Husband & 190 & $\mathbf{6 3 . 3}$ \\
Mother in law & 50 & 16.7 \\
Father in law & 15 & 5.0 \\
Adolescents mother & 16 & 5.3 \\
\hline \# Person who chooses food & & \\
Wife & 172 & $\mathbf{5 7 . 3}$ \\
Husband & 63 & 21.0 \\
Mother in law & 59 & 19.7 \\
Father in law & 3 & 1.0 \\
Adolescents mother & 18 & 6.0 \\
\hline \# Person who prepares food & & \\
Wife & 276 & $\mathbf{9 2 . 0}$ \\
Husband & 9 & 3.0 \\
Mother in law & 14 & 4.7 \\
Husband`s sister & 15 & 5.0 \\
Adolescents mother & 16 & 5.3 \\
Sister in law & 3 & 1.0 \\
\hline \hline
\end{tabular}

\# Categories are not mutually exclusive 


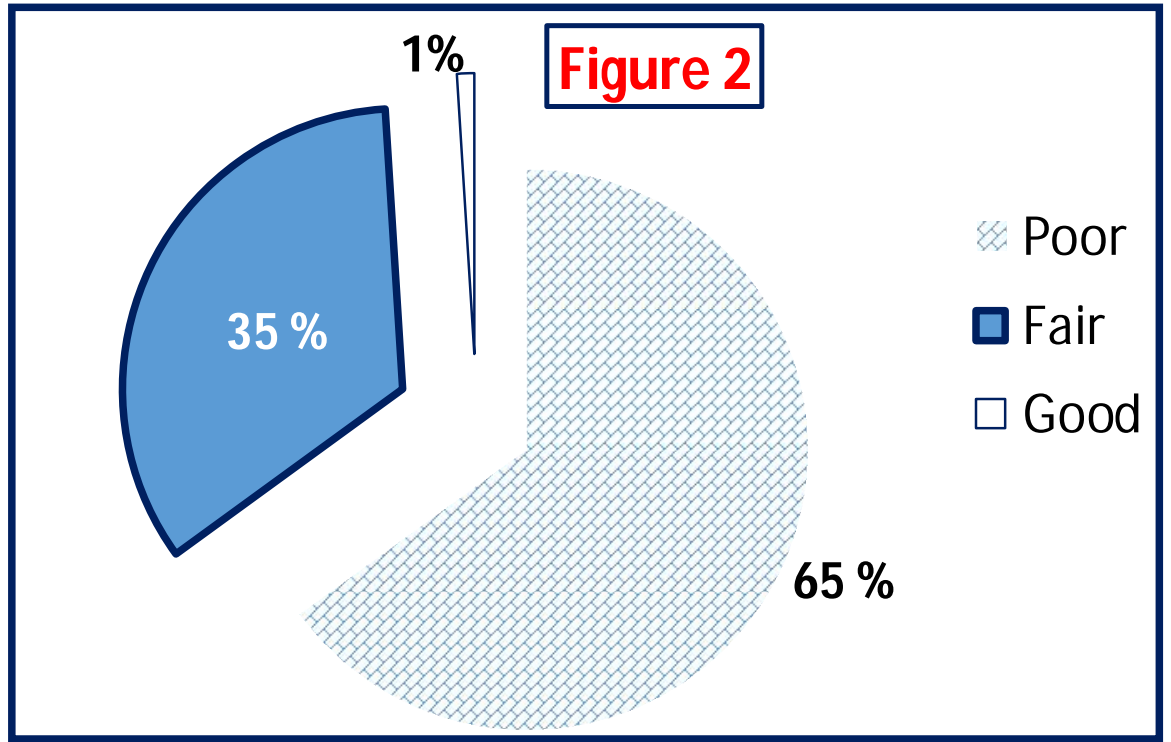

Figure (2): Percent distribution of the study sample according to their total score of knowledge about risks of malnutrition

Table (3): Number and percent distribution of the pregnant adolescents according to their knowledge about risks of malnutrition

\begin{tabular}{|c|c|c|c|c|c|c|}
\hline \multirow{3}{*}{ Knowledge about risks of malnutrition } & \multicolumn{6}{|c|}{$\begin{array}{c}\begin{array}{c}\text { Pregnant adolescents } \\
(\mathrm{n}=\mathbf{3 0 0})\end{array} \\
\end{array}$} \\
\hline & \multicolumn{2}{|c|}{$\begin{array}{l}\text { Wrong and } \\
\text { Don't know }\end{array}$} & \multicolumn{2}{|c|}{$\begin{array}{l}\text { Correct and } \\
\text { Incomplete }\end{array}$} & \multicolumn{2}{|c|}{$\begin{array}{l}\text { Correct and } \\
\text { Complete }\end{array}$} \\
\hline & No. & $\%$ & No. & $\%$ & No. & $\%$ \\
\hline $\begin{array}{l}\text { Risks of inadequate eating for mother during } \\
\text { pregnancy }\end{array}$ & 67 & 22.3 & 233 & 77.7 & 0 & 0.0 \\
\hline $\begin{array}{l}\text { Risks of lack of eating for fetus during } \\
\text { pregnancy }\end{array}$ & 99 & 33.0 & 198 & 66.0 & 3 & 1.0 \\
\hline $\begin{array}{l}\text { Risks of increase food intake for mother during } \\
\text { pregnancy }\end{array}$ & 190 & 63.3 & 110 & 36.7 & 0 & 0.0 \\
\hline $\begin{array}{l}\text { Risks of increase food intake for fetus during } \\
\text { pregnancy }\end{array}$ & 247 & 82.3 & 2 & 0.7 & 51 & 17.0 \\
\hline $\begin{array}{l}\text { Risks of increase intake of pickles and spicy } \\
\text { spices during pregnancy }\end{array}$ & 203 & 67.7 & 76 & 25.3 & 21 & 7.0 \\
\hline $\begin{array}{l}\text { Risks of iron deficiency in eating for mother } \\
\text { during pregnancy }\end{array}$ & 129 & 43.0 & 165 & $\mathbf{5 5 . 0}$ & 6 & 2.0 \\
\hline $\begin{array}{l}\text { Risks of iron deficiency in eating for fetus } \\
\text { during pregnancy }\end{array}$ & 185 & 61.7 & 112 & 37.3 & 3 & 1.0 \\
\hline $\begin{array}{l}\text { Risks of calcium deficiency in eating for } \\
\text { mother during pregnancy }\end{array}$ & 153 & 51.0 & 147 & 49.0 & 0 & 0.0 \\
\hline $\begin{array}{l}\text { Risks of calcium deficiency in eating for fetus } \\
\text { during pregnancy }\end{array}$ & 168 & 56.0 & 22 & 7.3 & 110 & 36.7 \\
\hline $\begin{array}{l}\text { Risks of vitamins deficiency in eating for } \\
\text { mother during pregnancy }\end{array}$ & 274 & 91.3 & 26 & 8.7 & 0 & 0.0 \\
\hline $\begin{array}{l}\text { Risks of vitamins deficiency in eating for fetus } \\
\text { during pregnancy }\end{array}$ & 190 & 63.3 & 107 & 35.7 & 3 & 1.0 \\
\hline
\end{tabular}

Mean \pm SD: $24.1 \pm 17.6$ 


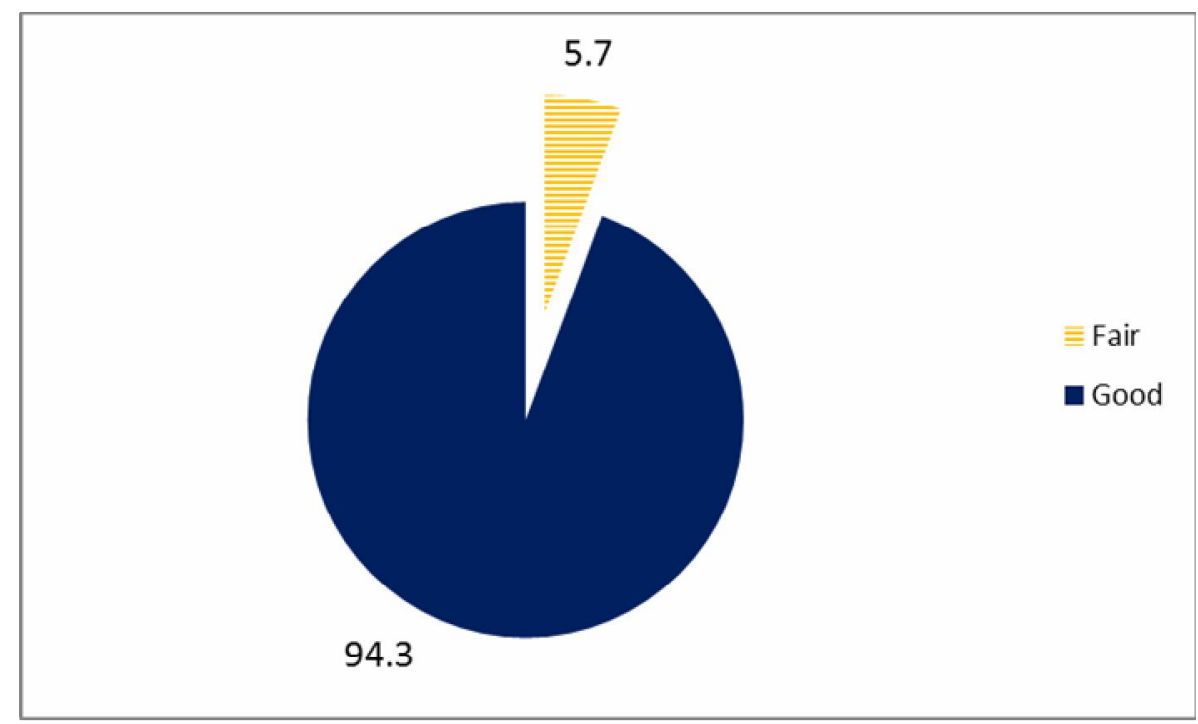

Figure (3): Percent distribution of the study sample according to their total score of nutritional habits\#

\# The study subjects with bad nutritional habits were omitted 
Table (4): The relationship between nutritional knowledge and elements of balanced diet of the pregnant adolescents and their socio-demographic data

\begin{tabular}{|c|c|c|c|c|c|c|c|c|}
\hline \multirow{3}{*}{\multicolumn{2}{|c|}{ Socio demographic data }} & \multicolumn{6}{|c|}{$\begin{array}{l}\text { Nutritional knowledge and elements of } \\
\text { balanced diet }\end{array}$} & \multirow{3}{*}{$M C P$} \\
\hline & & \multicolumn{2}{|c|}{ Poor (174) } & \multicolumn{2}{|c|}{ Fair (123) } & \multicolumn{2}{|c|}{ Good (3) } & \\
\hline & & No & $\%$ & No & $\%$ & No & $\%$ & \\
\hline \multirow{3}{*}{$\begin{array}{l}\text { Age } \\
\text { (In years) }\end{array}$} & $15-$ & 32 & 84.2 & 6 & 15.8 & 0 & 0.0 & \multirow{3}{*}{$0.005 *$} \\
\hline & 17- & 56 & 52.8 & 50 & 47.2 & 0 & 0.0 & \\
\hline & $19-21$ & 86 & 55.1 & 67 & 42.9 & 3 & 1.9 & \\
\hline \multirow{5}{*}{ Education } & Illiterate & 2 & 40.0 & 3 & 60.0 & 0 & 0.0 & \multirow{5}{*}{$0.000 *$} \\
\hline & Read and write & 20 & 87.0 & 3 & 13.0 & 0 & 0.0 & \\
\hline & $\begin{array}{l}\text { Preparatory school } \\
\text { education }\end{array}$ & 62 & 73.8 & 22 & 26.2 & 0 & 0.0 & \\
\hline & Secondary education & 86 & 51.5 & 78 & 46.7 & 3 & 1.8 & \\
\hline & University education & 4 & 19.0 & 17 & 81.0 & 0 & 0.0 & \\
\hline \multirow[b]{2}{*}{ Occupation } & Working & 8 & 23.5 & 23 & 67.6 & 3 & 8.8 & \multirow[b]{2}{*}{$0.000 *$} \\
\hline & $\begin{array}{l}\text { Not working } \\
\text { (Housewife) }\end{array}$ & 166 & 62.4 & 100 & 37.6 & 0 & 0.0 & \\
\hline \multirow{3}{*}{$\begin{array}{l}\text { Age of } \\
\text { marriage } \\
\text { (years) }\end{array}$} & $15-$ & 59 & 55.7 & 47 & 44.3 & 0 & 0.0 & \multirow{3}{*}{$0.007 *$} \\
\hline & $17-$ & 85 & 62.5 & 51 & 37.5 & 0 & 0.0 & \\
\hline & $19-21$ & 30 & 51.7 & 25 & 43.1 & 3 & 5.2 & \\
\hline \multirow{5}{*}{$\begin{array}{l}\text { Father } \\
\text { education }\end{array}$} & Illiterate & 41 & 47.7 & 42 & 48.8 & 3 & 3.5 & \multirow{5}{*}{$0.019 *$} \\
\hline & Read and write & 26 & 53.1 & 23 & 46.9 & 0 & 0.0 & \\
\hline & $\begin{array}{l}\text { Preparatory school } \\
\text { education }\end{array}$ & 25 & 75.8 & 8 & 24.2 & 0 & 0.0 & \\
\hline & Secondary education & 66 & 66.0 & 34 & 34.0 & 0 & 0.0 & \\
\hline & University education & 16 & 50.0 & 16 & 50.0 & 0 & 0.0 & \\
\hline \multirow{5}{*}{$\begin{array}{l}\text { Mother } \\
\text { education }\end{array}$} & Illiterate & 72 & 58.1 & 49 & 39.5 & 3 & 2.4 & \multirow{5}{*}{$0.009 *$} \\
\hline & Read and write & 20 & 42.6 & 27 & 57.4 & 0 & 0.0 & \\
\hline & $\begin{array}{l}\text { Preparatory school } \\
\text { education }\end{array}$ & 26 & 66.7 & 13 & 33.3 & 0 & 0.0 & \\
\hline & Secondary education & 52 & 69.3 & 23 & 30.7 & 0 & 0.0 & \\
\hline & University education & 4 & 26.7 & 11 & 73.3 & 0 & 0.0 & \\
\hline \multirow{2}{*}{$\begin{array}{l}\text { Type of } \\
\text { family }\end{array}$} & Nuclear & 127 & 58.8 & 86 & 39.8 & 3 & 1.4 & \multirow{2}{*}{0.469} \\
\hline & Extended & 47 & 56.0 & 37 & 44.0 & 0 & 0.0 & \\
\hline \multirow{3}{*}{$\begin{array}{l}\text { Crowding } \\
\text { index }\end{array}$} & $<1$ & 29 & 50.9 & 25 & 43.9 & 3 & 5.3 & \multirow{3}{*}{$0.007 *$} \\
\hline & $1-$ & 139 & 60.2 & 92 & 39.8 & 0 & 0.0 & \\
\hline & $3+$ & 6 & 50.0 & 6 & 50.0 & 0 & 0.0 & \\
\hline \multirow{3}{*}{ Income } & More than enough & 34 & 50.0 & 34 & 50.0 & 0 & 0.0 & \multirow{3}{*}{0.065} \\
\hline & Hardly enough & 100 & 56.5 & 74 & 41.8 & 3 & 1.7 & \\
\hline & Not enough & 40 & 72.7 & 15 & 27.3 & 0 & 0.0 & \\
\hline
\end{tabular}

MCP: P value based on Mont Carlo exact probability

$* \mathrm{P}<0.05$ (significant) 
Table (5): The relationship between knowledge about risks of malnutrition of the pregnant adolescents and their socio-demographic data

\begin{tabular}{|c|c|c|c|c|c|c|c|c|}
\hline \multirow{3}{*}{\multicolumn{2}{|c|}{ Socio demographic data }} & \multicolumn{6}{|c|}{ Knowledge about risks of malnutrition } & \multirow{3}{*}{$M C P$} \\
\hline & & \multicolumn{2}{|c|}{ Poor (195) } & \multicolumn{2}{|c|}{ Fair (102) } & \multicolumn{2}{|c|}{ Good (3) } & \\
\hline & & No & $\%$ & No & $\%$ & No & $\%$ & \\
\hline \multirow{3}{*}{$\begin{array}{l}\text { Age } \\
\text { (years) }\end{array}$} & $15-$ & 32 & 84.2 & 6 & 15.8 & 0 & 0.0 & \multirow{3}{*}{$0.019 *$} \\
\hline & $17-$ & 61 & 57.5 & 45 & 42.5 & 0 & 0.0 & \\
\hline & $19-21$ & 102 & 65.4 & 51 & 32.7 & 3 & 1.9 & \\
\hline \multirow{5}{*}{ Education } & Illiterate & 5 & 100.0 & 0 & 0.0 & 0 & 0.0 & \multirow{5}{*}{$0.004 *$} \\
\hline & Read and write & 20 & 87.0 & 3 & 13.0 & 0 & 0.0 & \\
\hline & $\begin{array}{l}\text { Preparatory school } \\
\text { education }\end{array}$ & 60 & 71.4 & 21 & 25.0 & 3 & 3.6 & \\
\hline & Secondary education & 99 & 59.3 & 68 & 40.7 & 0 & 0.0 & \\
\hline & University education & 11 & 52.4 & 10 & 47.6 & 0 & 0.0 & \\
\hline \multirow{2}{*}{ Occupation } & Working & 17 & 50.0 & 14 & 41.2 & 3 & 8.8 & \multirow[b]{2}{*}{$0.000 *$} \\
\hline & $\begin{array}{l}\text { Not working } \\
\text { (Housewife) }\end{array}$ & 178 & 66.9 & 88 & 33.1 & 0 & 0.0 & \\
\hline \multirow{3}{*}{$\begin{array}{l}\text { Age of } \\
\text { marriage } \\
\text { (years) }\end{array}$} & $15-$ & 74 & 69.8 & 29 & 27.4 & 3 & 2.8 & \multirow{3}{*}{0.054} \\
\hline & $17-$ & 88 & 64.7 & 48 & 35.3 & 0 & 0.0 & \\
\hline & $19-21$ & 33 & 56.9 & 25 & 43.1 & 0 & 0.0 & \\
\hline \multirow{5}{*}{$\begin{array}{l}\text { Father } \\
\text { education }\end{array}$} & Illiterate & 53 & 61.6 & 33 & 38.4 & 0 & 0.0 & \multirow{5}{*}{$0.001 *$} \\
\hline & Read and write & 28 & 57.1 & 18 & 36.7 & 3 & 6.1 & \\
\hline & $\begin{array}{l}\text { preparatory school } \\
\text { education }\end{array}$ & 21 & 63.6 & 12 & 36.4 & 0 & 0.0 & \\
\hline & Secondary education & 77 & 77.0 & 23 & 23.0 & 0 & 0.0 & \\
\hline & $\begin{array}{l}\text { University or more } \\
\text { education }\end{array}$ & 16 & $\mathbf{5 0 . 0}$ & 16 & 50.0 & 0 & 0.0 & \\
\hline \multirow{5}{*}{$\begin{array}{l}\text { Mother } \\
\text { education }\end{array}$} & Illiterate & 82 & 66.1 & 42 & 33.9 & 0 & 0.0 & \multirow{5}{*}{$0.009 *$} \\
\hline & Read and write & 26 & 55.3 & 18 & 38.3 & 3 & 6.4 & \\
\hline & $\begin{array}{l}\text { preparatory school } \\
\text { education }\end{array}$ & 24 & 61.5 & 15 & 38.5 & 0 & 0.0 & \\
\hline & Secondary education & 55 & 73.3 & 20 & 26.7 & 0 & 0.0 & \\
\hline & $\begin{array}{l}\text { University or more } \\
\text { education }\end{array}$ & 8 & 53.3 & 7 & 46.7 & 0 & 0.0 & \\
\hline \multirow{2}{*}{$\begin{array}{l}\text { Type of } \\
\text { family }\end{array}$} & Nuclear & 141 & 65.3 & 72 & 33.3 & 3 & 1.4 & \multirow{2}{*}{0.528} \\
\hline & Extended & 54 & 64.3 & 30 & 35.7 & 0 & 0.0 & \\
\hline \multirow{3}{*}{$\begin{array}{l}\text { Crowding } \\
\text { index }\end{array}$} & $<1$ & 33 & 57.9 & 24 & 42.1 & 0 & 0.0 & \multirow{3}{*}{0.067} \\
\hline & $1-$ & 150 & 64.9 & 78 & 33.8 & 3 & 1.3 & \\
\hline & $3+$ & 12 & 100.0 & 0 & 0.0 & 0 & 0.0 & \\
\hline \multirow{3}{*}{ Income } & More than enough & 38 & 55.9 & 30 & 44.1 & 0 & 0.0 & \multirow{3}{*}{$0.010 *$} \\
\hline & Hardly enough & 111 & 62.7 & 63 & 35.6 & 3 & 1.7 & \\
\hline & Not enough & 46 & 83.6 & 9 & 16.4 & 0 & 0.0 & \\
\hline
\end{tabular}

MCP: P value based on Mont Carlo exact probability

$* \mathrm{P}<0.05$ (significant) 
Table (6): The relationship between nutritional habit of the pregnant adolescents and their socio-demographic data

\begin{tabular}{|c|c|c|c|c|c|c|}
\hline \multirow{3}{*}{\multicolumn{2}{|c|}{ Socio demographic data }} & \multicolumn{4}{|c|}{ Nutritional habit } & \multirow{3}{*}{$M C P$} \\
\hline & & \multicolumn{2}{|c|}{ Fair (17) } & \multicolumn{2}{|c|}{ Good (283) } & \\
\hline & & No & $\%$ & No & $\%$ & \\
\hline \multirow{3}{*}{$\begin{array}{l}\text { Age } \\
\text { (years) }\end{array}$} & $15-$ & 3 & 7.9 & 35 & 92.1 & \multirow{3}{*}{$0.012 *$} \\
\hline & 17- & 11 & 10.4 & 95 & 89.6 & \\
\hline & $19-21$ & 3 & 1.9 & 153 & 98.1 & \\
\hline \multirow{5}{*}{ Education } & Illiterate & 0 & 0.0 & 5 & 100.0 & \multirow{5}{*}{0.414} \\
\hline & Read and write & 3 & 13.0 & 20 & 87.0 & \\
\hline & preparatory school education & 5 & 6.0 & 79 & 94.0 & \\
\hline & Secondary education & 9 & 5.4 & 158 & 94.6 & \\
\hline & University education & 0 & 0.0 & 21 & 100.0 & \\
\hline \multirow{2}{*}{ Occupation } & Work & 3 & 8.8 & 31 & 91.2 & \multirow{2}{*}{$0.398 !$} \\
\hline & not work (Housewife) & 14 & 5.3 & 252 & 94.7 & \\
\hline \multirow{3}{*}{\begin{tabular}{|l} 
Age of \\
Marriage \\
(years)
\end{tabular}} & $15-$ & 12 & 11.3 & 94 & 88.7 & \multirow{3}{*}{$0.004 *$} \\
\hline & $17-$ & 5 & 3.7 & 131 & 96.3 & \\
\hline & $19-21$ & 0 & 0.0 & 58 & 100.0 & \\
\hline \multirow{5}{*}{$\begin{array}{l}\text { Father } \\
\text { education }\end{array}$} & Illiterate & 6 & 7.0 & 80 & 93.0 & \multirow{5}{*}{0.266} \\
\hline & Read and write & 3 & 6.1 & 46 & 93.9 & \\
\hline & preparatory school education & 0 & 0.0 & 33 & 100.0 & \\
\hline & Secondary education & 8 & 8.0 & 92 & 92.0 & \\
\hline & University or more education & 0 & 0.0 & 32 & 100.0 & \\
\hline \multirow{5}{*}{$\begin{array}{l}\text { Mother } \\
\text { education }\end{array}$} & Illiterate & 8 & 6.5 & 116 & 93.5 & \multirow{5}{*}{0.084} \\
\hline & Read and write & 6 & 12.8 & 41 & 87.2 & \\
\hline & preparatory school education & 0 & 0.0 & 39 & 100.0 & \\
\hline & Secondary education & 3 & 4.0 & 72 & 96.0 & \\
\hline & University or more education & 0 & 0.0 & 15 & 100.0 & \\
\hline \multirow{2}{*}{ Type of family } & Nuclear & 11 & 5.1 & 205 & 94.9 & \multirow{2}{*}{$0.490 !$} \\
\hline & Extended & 6 & 7.1 & 78 & 92.9 & \\
\hline \multirow{3}{*}{$\begin{array}{l}\text { Crowding } \\
\text { index }\end{array}$} & $<1$ & 0 & 0.0 & 57 & 100.0 & \multirow{3}{*}{$0.003 *$} \\
\hline & $1-$ & 14 & 6.1 & 217 & 93.9 & \\
\hline & $3+$ & 3 & 25.0 & 9 & 75.0 & \\
\hline \multirow{3}{*}{ |ncome } & More than enough & 0 & 0.0 & 68 & 100.0 & \multirow{3}{*}{$0.000 *$} \\
\hline & Hardly enough & 3 & 1.7 & 174 & 98.3 & \\
\hline & not enough & 14 & 25.5 & 41 & 74.5 & \\
\hline
\end{tabular}

MCP: P value based on Mont Carlo exact probability

$* \mathrm{P}<0.05$ (significant)

!: P value based on Fisher Exact probability

\# The study subjects have no bad nutritional habits so it is omitted from the table 


\section{References}

1. Aria L. Teenage pregnancy: The making and unmaking of the problem. British Library Cataloguing; 2009. P. 37.

2. El Nouman A, El Derwi D, Abdel Hai R. Female youth health promotion model in primary health care: a community-based study in rural Upper Egypt. Eastern Mediterranean Health Journal 2009; 15(6):1513-24.

3. WHO. Pregnancy [Internet]. 2013. Available at: http://www.who.int/topics/pregnancy/e/ Retrieved on: 15 March 2013.

4. Ebrahim GJ. Nutrition in mother and child health. Hong Kong: Macmillan Press; 1983. P. 34-52.

5. Index Mundi. Egypt Demographics Profile [Internet]. 2014. Available at: http://www.indexmundi.com/egypt/dem ographics profile.html. Retrieved on: 21 August 2014.

6. Geissler CA, Powers HJ. Human nutrition. $11^{\text {th }}$ ed. China: Elsevier Limited C.; 2005. P. 300-7.

7. WHO. Global health observatory data repository: Egypt statistics summary (2002 - present) [Internet]. 2014. Available at: http://apps.who.int/gho/data/node.countr y.country-EGY. Retrieved on: 21 August 2014.

8. WHO. Maternal, newborn, child and adolescent health. Adolescent pregnancy [Internet] 2013. Available at: http://www.who.int/maternal_child_ado lescent/topics/maternal/adolescent_preg nancy/en/. Retrieved on: 10 December 2013.

9. The World Bank, United Nations Population Division, world population prospects. Maternal Mortality [Public Health at a Glance] [Internet]. 2006
Available at: http://data.worldbank.org/indicator/SP. ADO.TFRT/countries/1W?display=defa ult. Retrieved on: 21 August 2014.

10. Jivraj S, Nazzal Z, Davies P. Obstetric outcome of teenage pregnancies from 2002 to 2008: The Sheffield experience. Journal of Obstetrics and Gynecology 2010; 30(3): 253-6.

11. Adeyinka DA, Adekanbi TI, Folasade E. Outcome of adolescent pregnancies in southwestern Nigeria: a case-control study. The Journal of Maternal-Fetal and Neonatal Medicine 2010; 23(8): 785-9.

12. Roudi-Fahimi F, Ibrahim S. Ending child marriage in the Arab region [Internet]. 2013. available at: http://www.prb.org/pdf13/childmarriage-arab-region.pdf. Retrieved on: 21 August 2014.

13. WHO, Egypt country profile. Department of making pregnancy safer. Analysis of demographic and health surveys [Internet]. 2008. Available at: http://www.who.int/maternal child ado lescent/countries/egy rev.pdf. Retrieved on: 21 August 2014.

14. Rasheed S, Abdelmonem A, Amin M. Adolescent pregnancy in Upper Egypt. International Journal of Gynecology and Obstetrics 2011; 112: 21-4.

15. World Health Organization. Nutrition in adolescence: issues and Challenges for the Health Sector: Issues in Adolescent Health and Development. Geneva, 2005.

16. Moukhyer ME, van Eijk JT. Health related behaviors of Sudanese adolescents. Educ Health (Abingdon) 2008; 21(1):184.

17. Mogler C. Adolescence. Grin Verlag 2008; 5: 2-6. 
18. Bauer KW. The family environment and adolescent girls' weight and weight related behaviors: Implications for obesity prevention programs $[\mathrm{PhD}$ Thesis]. Faculty of the Graduate School, University of Minnesota; 2010.

19. Goicolea I. Adolescent pregnancies in the Amazon Basin of Ecuador: a rights and gender approach to adolescents' sexual and reproductive health. Global Health Action 2010, 3: 5280.

20. Papes MA. Fast food and risks of overweight among adolescent in the clue cohert $[\mathrm{PhD}$ Thesis]. Baltimore, Maryland: Johons University; 2006.

21. Videon TM, Manning CK. Influences on adolescent eating patterns: the importance of family meals. Journal of Adolescent Health Volume 2003; 32 (5): 365-73.

22. Azizi MN, Ebrahimi AM, Ranjbar K. Nutrition knowledge, the attitude and practices of college students. Physical education and sport 2011; 9(3): 349 57.

23. Okubo H, Murakami SP, Takahashi Y. Nutritional adequacy of four dietary patterns defined by cluster analysis in Japanese women aged 18-20 years. Asia Pac J Clin Nutr 2010; 19 (4): 555-63.

24. Vereecken A, Covents M, Matthys C. Young adolescents' nutrition assessment on computer. European Journal of Clinical Nutrition 2005; 59 : 658-67.

25. Moran VH. Nutritional status in pregnant adolescents: a systematic review of biochemical markers. Maternal and Child Nutrition: Blackwell Publishing Ltd; 2007. P. 374-93.

26. Shaaban SY, Nassar MF, Abd Elhamid DM, El-Batrawy SR, Lasheen RA. Nutritional Knowledge and Attitude of
Adolescent School Girls Living in Cairo. Research Journal of Medicine and Medical Sciences 2009; 4(2): 421 7.

27. Story M, Stang J, editors. Nutrition and the pregnant adolescent: A practical reference Guide. Minneapolis, $\mathrm{MN}$ : center for leadership, education, and Training in Maternal and Child Nutrition, University of Minnesota, 2000 .

28. Williamson CS. Nutrition in pregnancy. Nutrition Bulletin 2006; 31(1): 28-59.

29. Stevenson C, Doherty G, Barnett J. Adolescents' views of food and eating: Identifying barriers to healthy eating. Journal of Adolescence 2007; 30: $417-$ 34.

30. Preedy VR, Watson RR, Matrin CR. Handbook of behavior, food and nutrition. London: Springer Science; 2011. P. 758-62.

31. Contento IR. Nutrition education linking research, theory, and practice: 2nd ed. Jones \& Bartlett Publishers; 2011. P. 26-42.

32. Gray SK, Kin HB. Nutritional knowledge, eating habits, and body image of adolescent females. [Master Thesis]. Faculty of Education, University of Brock; 2009.

33. Fsmaillzadch A, Samarch S, Azadbakht L. Dietary patterns among pregnant women in the West North of Iran. Pakistan Journal of Biological Sciences 2008; 11(5): 793-6.

34. Food today why we eat what we eat: social and economic determinants of food choice [Internet]. 2004. Available at:

http://www.eufic.org/article/en/healthand-lifestyle/food-choice/artid/socialeconomic-determinants-food-choice/. Retrieved on: July 2014. 
35. Senderowitz J. Adolescent health: Reassessing the passage to adulthood. United State of America: The world Bank Washington D C.; 1995. P. 2.

36. Hassanain RA, Mohamed SN, Ahmed NH. Assessment of female adolescent reproductive health needs in Assiut city. Journal of American Science 2011; 7(8): 207-20.

37. Lee RD, Nieman DC. Nutritional assessment. United States of America: WM.C. Brown Communications, Inc.; 1993.P. 35-6.

38. Olaitan O L. Risks experience during pregnancy among teenagers in South West Nigeria. International. Journal of Collaborative Research on Internal Medicine \& Public Health 2012; 1(4): $1-12$.

39. Yassin S. Factors affecting dietary practices among adolescent pregnant women in Alexandria. J Egypt Public Health Assoc 2004; 79 (3-4):179-96.

40. Özünlü T, Cetinkaya S. The relation between pregnant adolescents' attitude about nutrition and weight gain during pregnancy and hemoglobin level. Journal of Obstetrics and Gynecology 2013; 3: 172-9.
41. Daba G. Assessment of knowledge of pregnant mothers on maternal nutrition and associated factors in Guto Gida Woreda, East Wollega Zone, Ethiopia. J Nutr Food Sci 2013; 3 (6) 235-42.

42. Alam N, Roy SK, Ahmed T. Nutritional status, dietary intake, and relevant knowledge of adolescent girls in rural Bangladesh. Journal of Health, Population and Nutrition 2010; 28 (1): 86-94.

43. Wise NJ, Arcamone AA. Survey of adolescent views of healthy eating during pregnancy. MCN Am J Matern Child Nurs 2011; 36(6):381-6.

44. Hassan MI. Relationship between so cio-economic characteristics, health status and nutritional awareness of pregnant women. Paper presented at: managing knowledge and intellectual capital in Higher Education institutions in Egypt and Arab World; 2012 April 11-12; Faculty of Specific Education, Mansoura University. P. 1802-14.

45. Mirsanjari M. Relationship between nutritional knowledge and healthy attitude and practice during pregnancy. Borneo Science 2012; 31: 104-12. 